\title{
A localized intimomedial defect resulted in aortic regurgitation
}

\author{
Naoto Morimoto, MD, Yutaka Okita, MD, Kenji Okada, MD, Teruo Yamashita, MD, Keitaro Nakagiri, MD, \\ Ayako Maruo, MD, Yujiro Kawanishi, MD, Masamichi Matsumori, MD, and Mitsuru Asano, MD, Kobe, Japan
}

A

cute aortic regurgitation is usually caused by aortic dissection and infective endocarditis. We describe an unusual cause of acute aortic regurgitation caused by the dislocation of the commissure, along with the localized defect of the inner side of the aorta. Histologic study disclosed that the intimal tear extended deep into all layers of the media (an "intimomedial tear") and caused acute aortic regurgitation through dislocation of the commissure.

\section{Clinical Summary}

A 41-year-old man with a diagnosis of annuloaortic ectasia and aortic insufficiency was referred to our hospital. He had acute onset of anterior neck and chest pain and was transferred to a local hospital before being transferred to ours. The results of coronary angiography were normal. An aortography showed a moderately dilated ascending aorta and grade 3/4 aortic regurgitation (Figure 1).

He was in New York Heart Association functional class II with grade III/VI diastolic murmur. Transesophageal echocardiography revealed a moderately dilated left ventricle with normal systolic function, no thickening of the aortic cusps, and prolapse of the right coronary cusp with severe aortic regurgitation. The aorta was dilated, measuring $25 \mathrm{~mm}$ at the aortic annulus, $49 \mathrm{~mm}$ at the sinus of Valsalva, and $40 \mathrm{~mm}$ at the sinotubular junction.

Surgical intervention was performed 2 months after the onset. The aortic root was spherically dilated, and the left side of the aorta was densely adherent to the pulmonary trunk as in chronic aortic dissection. After cardioplegic arrest, the aorta was open. No aortic dissection and detachment of the aortic commissure were present. The half-circumscribed sharp-edged defect at the inner side of the aortic wall extended between the right and left coronary ostium near the sinotubular junction, being $3 \mathrm{~cm}$ in length. The commissure between the right and left coronary cusps was dislocated from the sinotubular junction over a sector of approximately $1 \mathrm{~cm}$ (Figure 1). The tissue of the commissure itself was intact, and the right coronary cusp was redundant. A valve-sparing procedure (reimplantation technique) was performed with a self-made 26-mm Dracon polyester fabric Valsalva graft.

From the Divisions of Cardiovascular, Thoracic, and Pediatric Surgery, Kobe University graduate school of Medicine, Kobe, Japan.

Received for publication Aug 7, 2005; revisions accepted Sept 2, 2005; accepted for publication Sept 9, 2005.

Address for reprints: Naoto Morimoto, MD, Division of Cardiovascular, Thoracic, and Pediatric Surgery, Kobe University Graduate School of Medicine, 7-5-2 Kusunoki-cho, Chuo-ku, Kobe 650-0017, Japan (E-mail: naotom@juno.ocn.ne.jp).

J Thorac Cardiovasc Surg 2006;131:232-3

$0022-5223 / \$ 32.00$

Copyright (C) 2006 by The American Association for Thoracic Surgery doi:10.1016/j.jtcvs.2005.09.009

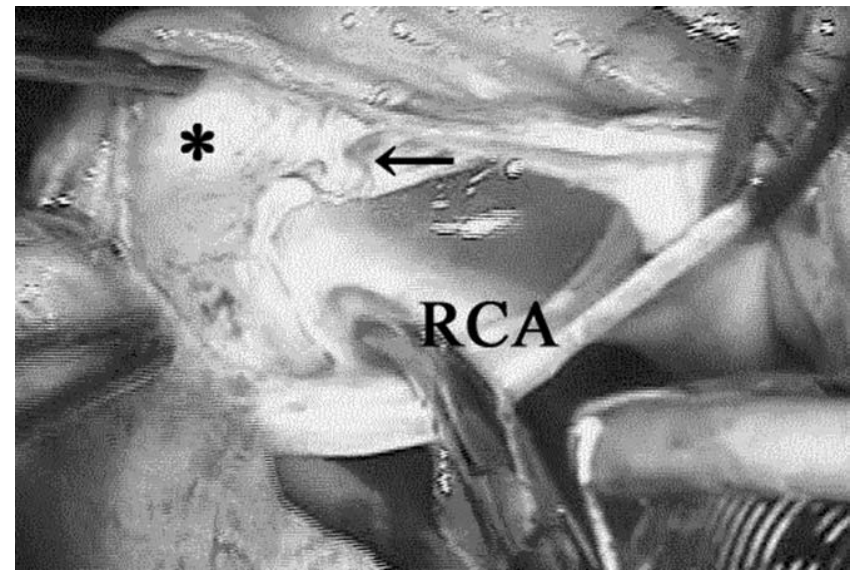

Figure 1. Inner aspect of the aorta with a lesion characterized by a sharply delineated shallow defect (asterisk). The aortic annulus was deformed by dislocation of the commissure between the right and left coronary cusps (arrow). RCA, Right coronary artery ostium.

Histopathology reports disclosed the presence of cystic medial necrosis in the ascending aorta. The defect at the inner side of the aorta extends throughout all layers of the media and reaches the adventitia. The outer part of the defect still contains elastin fibers of the original media. The luminal side of the defect is covered by fibrocellular proliferation (Figure 2). These findings suggest the sudden interruption of the preexistent structure caused by an abrupt laceration, as in aortic dissection.

The postoperative course was uneventful, and echocardiography revealed no evidence of aortic regurgitation. The patient is in good clinical condition 3 months after the operation.

\section{Discussion}

It is well known that Stanford type A aortic dissection occasionally induces aortic regurgitation. The mechanism of aortic regurgitation has been explained by showing that the aortic annulus is transformed by the markedly enlarged false lumen and the separation of the cusp commissure. In the present case aortic regurgitation and aortic cusp prolapse occurred as a consequence of dislocation of the commissure of the right and left coronary cusps to intimomedial tear.

In classical aortic dissection delamination of media follows primary intimal tear and extends up to the inner two thirds of media. It never reaches the adventitia. ${ }^{1}$ This variant type of dissection has been called incomplete dissection, ${ }^{2}$ limited dissection, ${ }^{3}$ class 3 dissection, ${ }^{4}$ or partial intimal tear "stretch mark." ${ }^{5}$ Schlatmann and Becker ${ }^{2}$ reported the localized defect in the inner side of 


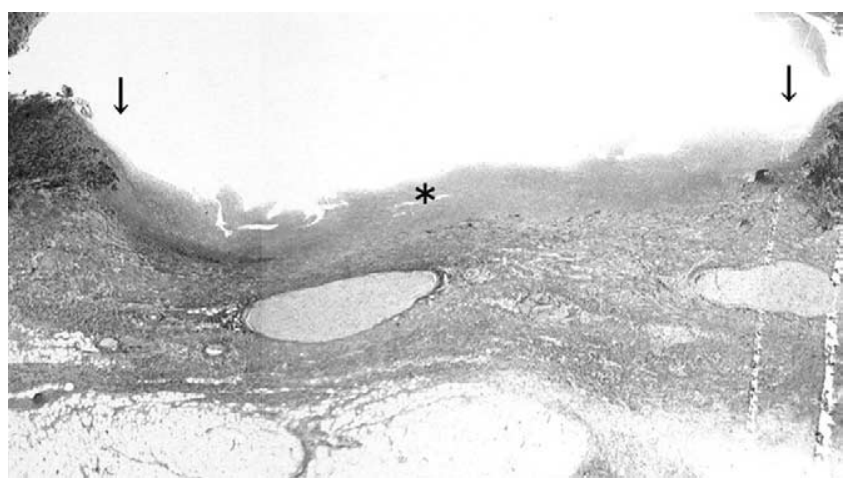

Figure 2. Histologic section (elastica van Gieson stain) through the area that shows abrupt laceration (arrow) of all the layers of media. The outer part of the defect contains only the adventitia. The luminal side of the defect is covered by fibrocellular proliferation (asterisk).

the aorta in 9 patients with Marfan syndrome, coactation of the aorta, or chronic aortic dissection by autopsy. Histologic section revealed almost the same findings as in the present case. The mechanism of the occurrence of intimomedial tear could be associated with fragility of the aortic wall, such as cystic medial necrosis and Marfan syndrome. Svensson and colleagues ${ }^{3,4}$ also reported this type of tear in $6.6 \%$ of patients with Marfan syndrome and suspected that it might propagate to become the classical type of aortic dissection.

In this case intimomedial tear occurred in the aorta facing the pulmonary trunk and did not result in aortic rupture or pseudoaneurysm formation but in aortic regurgitation.

Intimomedial tear of the aortic wall around the aortic commissure is a rare pathophysiologic cause of acute aortic regurgitation. The occurrence of intimomedial tear might be associated with fragility of the aortic wall, such as cystic medial necrosis. If acute aortic regurgitation with aortic cusp prolaspe and intact ascending aortic wall is present in the patients with connective tissue disease, intimomedial tear of the aortic commissure should be taken into consideration.

\section{References}

1. Roberts WC. Aortic dissection: anatomy, consequences and causes. Am Heart J. 1981;191:195-214.

2. Schlatmann TJ, Becker AE. Pathogenesis of dissecting aneurysm of aorta. Comparative histopathologic study of significance of medial changes. Am J Cardiol. 1977;39:21-6.

3. Svensson LG, Crawford ES, Coselli JS, Safi HJ, Hess KR. Impact of cardiovascular operation on survival in the Marfan patient. Circulation. 1989;80(suppl I):I233-42.

4. Svensson LG, Labib SB, Eisenhauer AC, Butterly JR. Intimal tear without hematoma: an important variant of aortic dissection that can elude current imaging techniques. Circulation. 1999;99:1331-6.

5. Fleischmann D, Rubin G. Multidetector CT of the Vascular System. Presented at: Radiological Society of North America Scientific Assembly and Annual Meeting; 2004.

\section{Novel left ventriculoplasty for nonischemic dilated cardiomyopathy with functional mitral regurgitation}

Hiroshi Irie, MD, PhD, Tadashi Isomura, MD, PhD, Fumikazu Nomura, MD, PhD, Taiko Horii, MD, PhD, Joji Hoshino, MD, Haruka Makinae, MD, and Hisayoshi Suma, Kanagawa, Japan

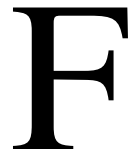
unctional mitral regurgitation (FMR) accompanying nonischemic dilated cardiomyopathy (DCM) has a poor prognosis, and its surgical management is still controversial. We report a novel surgical approach that consists of the repair of papillary muscle geometry and annuloplasty with

\footnotetext{
From the Department of Cardiothoracic Surgery, Hayama Heart Center, Kanagawa, Japan.

Received for publication June 25, 2005; revisions accepted Aug 30, 2005; accepted for publication Sept 9, 2005.

Address for reprints: Tadashi Isomura, MD, PhD, Department of Cardiothoracic Surgery, Hayama Heart Center, 1898 Shimoyamaguchi, Hayama, Kanagawa, 240-0116, Japan (E-mail: isomura@ hayamaheart.gr.jp).

J Thorac Cardiovasc Surg 2006;131:233-5

$0022-5223 / \$ 32.00$

Copyright $\odot 2006$ by The American Association for Thoracic Surgery

doi:10.1016/j.jtcvs.2005.09.010
}

a semirigid ring and partial resection of the dilated left ventricle (LV). Mid-term postoperative results of our surgical approach included no recurrence of FMR, effective reduction of the LV volume and shape, and improvement of pulmonary artery pressure.

\section{Clinical Summary}

A 42-year-old man was admitted to our center for an easy fatigability on effort. On admission, echocardiogram demonstrated a dilated LV associated with severe mitral valve regurgitation. Endsystolic volume index (ESVI) and end-diastolic volume index (EDVI) were 139.5 and $160.5 \mathrm{~mL} / \mathrm{m}^{2}$, respectively. Although severe regurgitation was present either at the mitral $(3+)$ or tricuspid valve $(3+)$, ejection fraction $(\mathrm{EF})$ was decreased to 13 percentages, and pulmonary artery systolic pressure (PAP) was increased to $39 \mathrm{~mm} \mathrm{Hg}$. Preoperative gated single photon emission computed tomography quantification confirmed the diagnosis of DCM and showed the spherical shape of the dilated LV. Coronary angiography showed normal coronary findings. 